
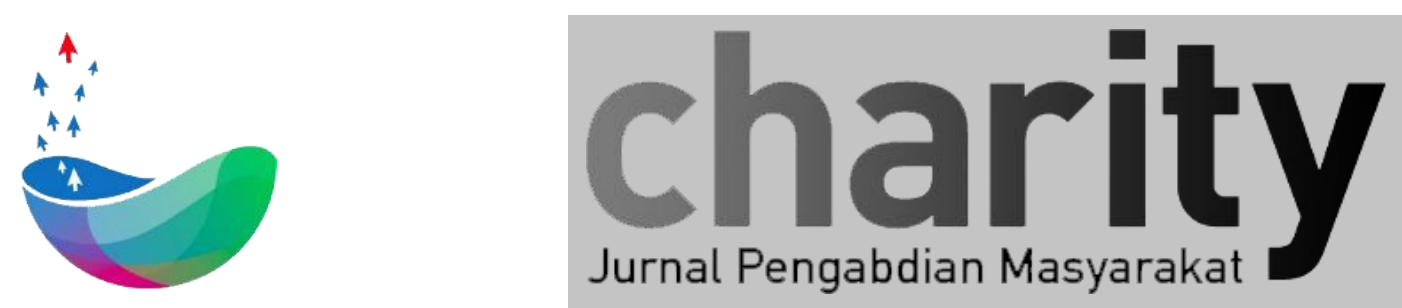

\title{
Pengukuran Customer Satisfaction Index Implementasi Mobile Version Portal Wisata Garut
}

Anisa Herdiani ${ }^{1}$, Indra Lukmana Sardi ${ }^{2}$, Arief Budiman ${ }^{3}$, Sakina Fathiani ${ }^{4}$, Novian Denny Nugraha ${ }^{5}$, Dawam Dwi Jatmiko $^{6}$, Adiwijaya ${ }^{6}$

${ }^{1}$ Fakultas Informatika, Universitas Telkom

${ }^{2}$ Fakultas Informatika, Universitas Telkom

${ }^{3}$ Fakultas Industri Kreatif, Universitas Telkom

${ }^{4}$ Fakultas Industri Kreatif, Universitas Telkom

Fakultas Industri Kreatif, Universitas Telkom

${ }^{6}$ Fakultas Informatika, Universitas Telkom

Fakultas Informatika, Universitas Telkom

* anisaherdiani@telkomuniversity.ac.id, indraluk@telkomuniversity.ac.id, ariefiinkemail@telkomuniversity.ac.id

\section{INFO ARTIKEL}

Diterima 03 Februari 2020

Direvisi 12 Juli 2020

Disetujui 27 Agustus 2020

Tersedia Online 28 Agustus 2020

\begin{abstract}
ABSTRAK
Kabupaten Garut merupakan daerah dengan berbagai destinasi wisata yang menarik dikunjungi wisatawan baik dari dalam maupun luar negeri. Hingga saat ini Dinas Pariwisata Kabupaten Garut telah memiliki portal wisata berbasis web yang dikembangkan bersama dengan Universitas Telkom. Portal wisata tersebut mengakomodasi informasi tempat pariwisata, tempat menginap, produk atau layanan jasa yang ditawarkan, serta fitur informasi wisata halal yang tentunya sangat penting diketahui oleh wisatawan muslim.

Portal wisata kemudian perlu dikembangkan lebih lanjut agar dapat lebih mudah dijangkau oleh calon wisatawan yang mengakses informasi melalui perangkat mobile. Portal versi mobile dikembangkan dengan teknologi PWA (Progressive Web Application) sehingga user dapat merasakan experience penggunaan aplikasi mobile tanpa perlu mengunduh aplikasi untuk mengakses informasi yang ada di dalam portal wisata.

Untuk mengukur tingkat kepuasan pengguna informasi terhadap portal wisata yang sudah dibangun, dilakukan evaluasi yang menghasilkan Customer Satisfaction Index (CSI). Hasil evaluasi menunjukkan CSI yang dicapai oleh portal yang sudah dibangun yaitu sebesar 90,5\% dengan interpretasi Sangat Baik.
\end{abstract}

Keyword: CSI, Kabupaten Garut, Portal Wisata.

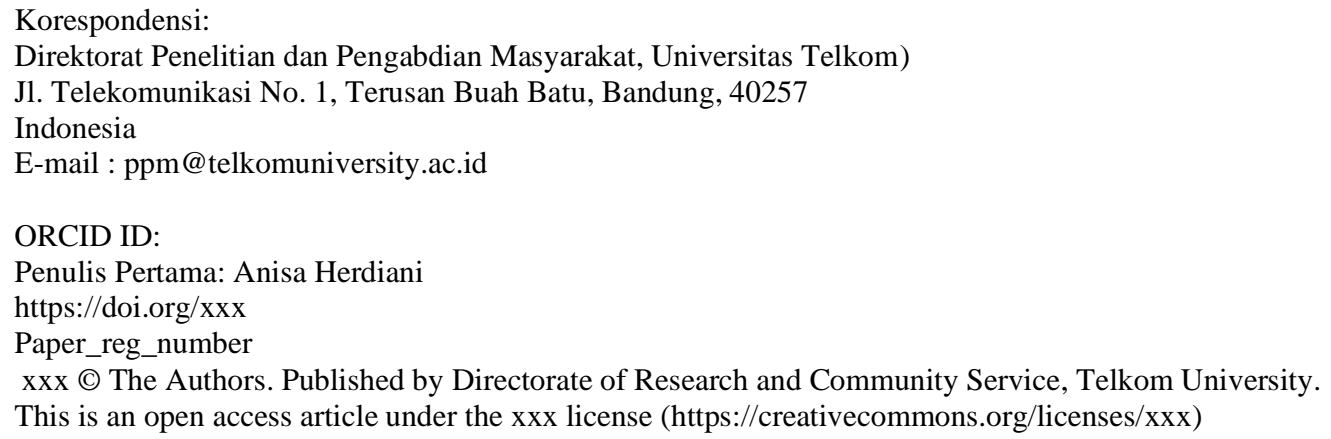




\section{Pendahuluan}

Pariwisata merupakan sektor penting dalam ekonomi Indonesia. Berdasarkan data dari Badan Pusat Statistik pada laman https://www.bps.go.id/, proporsi kontribusi pariwisata terhadap Pendapatan Domestik Bruto (PDB) pada tahun 2017-2019 mencapai 4\% dengan Jawa Barat sebagai kontributor tertinggi yang mendatangkan wisatawan yaitu sebesar $16 \%$.

Kabupaten Garut merupakan daerah dengan berbagai destinasi wisata yang menarik dikunjungi wisatawan baik dari dalam maupun luar negeri. Namun demikian, sampai dengan tahun 2016, Kab Garut belum memiliki database destinasi wisata dan portal wisata dalam bentuk website dengan domain go.id. Pegawai yang dimiliki Dinas Pariwisata dan Kebudayaan Kab. Garut juga tidak memiliki tenaga ahli untuk dapat mengelola website sebagai media promosi pariwisata.

Untuk mengatasi hal tersebut, Dinas Pariwisata Kabupaten Garut bekerja sama dengan Universitas Telkom melalui program Pengabdian Kepada Masyarakat telah membangun portal wisata dengan alamat http://visitgarut.garutkab.go.id/. Portal wisata tersebut mengakomodasi informasi tempat pariwisata, tempat menginap, produk atau layanan jasa yang ditawarkan, dashboard wisatawan, pembuatan template bilingual, dan managemen admin yang memberikan akses kolaborasi bagi admin hotel, restoran, travel serta fitur informasi wisata halal yang tentunya sangat penting diketahui oleh wisatawan muslim.

Seiring berjalannya waktu, untuk mengakomodasi berbagai kebutuhan pencari informasi wisata yang menginginkan kemudahan dalam mengakses informasi, diperlukan versi mobile dari portal wisata yang mudah digunakan oleh pengguna. Versi mobile dari portal wisata ini dibangun dengan menggunakan teknologi PWA yaitu Progressive Web Application yang memungkinkan pengguna mengakses informasi di portal wisata, dengan experience seperti menggunakan aplikasi mobile. Setelah versi mobile ini dibangun, kemudian dilakukan pengukuran kepuasan pengguna informasi terhadap portal wisata yang telah dibangun, dengan parameter pengukuran Customer Satisfaction Index (CSI). 


\section{Portal Wisata berbasis Progressive Web Application}

Pembangunan mobile version dari portal visit garut dilakukan menggunakan teknologi Progressive Web Application (PWA). PWA merupakan user experience yang didapatkan dari web, yang memiliki karakteristik (1) Reliable yaitu sistem akan menyajikan konten web secara instan bahkan dalam kondisi ketidakstabilan jaringan, (2) Fast yaitu sistem akan merespon secara cepat setiap interaksi dari user dengan menampilkan animasi, dan (3) Engaging yaitu sistem akan terasa sebagai sebuah aplikasi yang dijalankan di perangkat, dengan user experience yang mendalam (Google Developers, 2019).

Tampilan utama portal wisata versi mobile dengan menerapkan teknologi PWA dapat dilihat pada Gambar 1. Tampilan menu portal wisata dapat dilihat pada Gambar 2. Tampilan informasi tempat wisata dapat dilihat pada Gambar 3 .
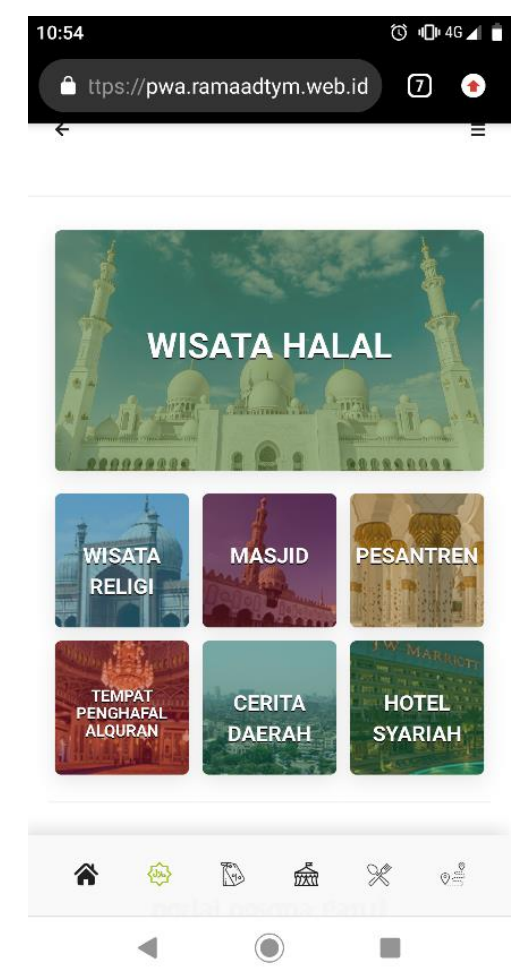

Gambar 1 Tampilan Utama Portal Wisata Garut Versi Mobile

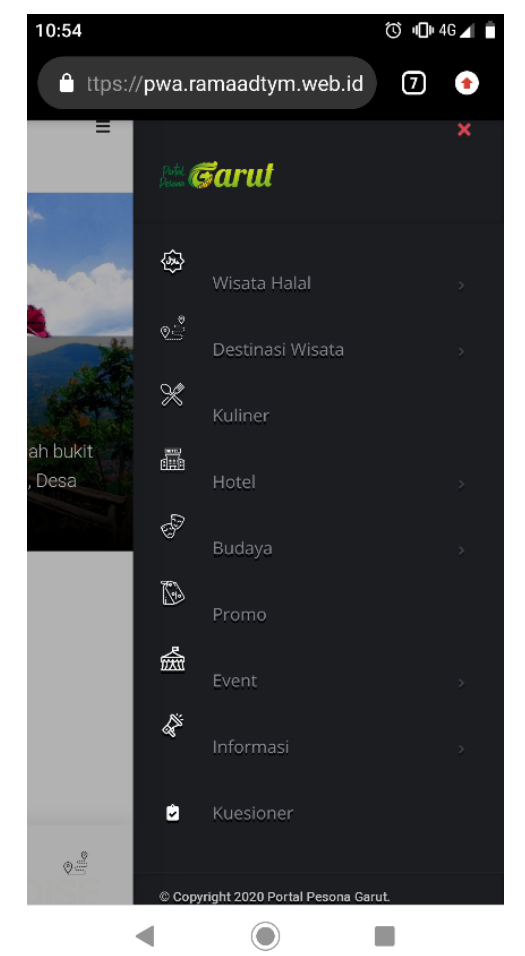

Gambar 2 Tampilan Menu Portal Wisata Garut Versi Mobile 


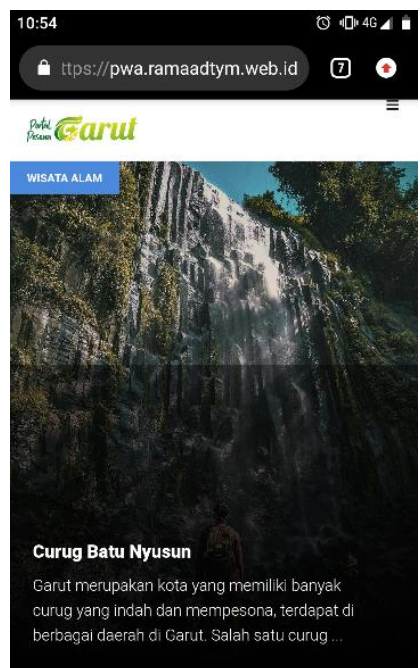

Gambar 3 Tampilan Informasi Tempat Wisata Portal Wisata Garut Versi Mobile

\section{Customer Satisfaction Index}

Customer Satisfaction Index (CSI) merupakan parameter yang digunakan untuk mengetahui tingkat kepuasan pengguna jasa secara menyeluruh dengan melihat tingkat kinerja dan tingkat kepentingan atau harapan dari atributatribut jasa pelayanan (Khairul Umam, 2018).

\subsection{Kriteria Penilaian}

Atribut pertanyaan yang digunakan untuk penilaian CSI pada layanan website dibuat berdasarkan pada kriteria WEBQUAL yang merupakan instrumen yang digunakan untuk menilai kualitas dari website. Instrumen pada WEBQUAL terdiri atas empat kriteria yaitu usefulness, ease of use, entertainment, dan complimentary relationship (Barner, 2000). Proses penyesuaian atribut WEBQUAL ke instrumen yang digunakan untuk mendapatkan nilai CSI dapat dilihat pada Tabel 1.

Tabel 1 Pemetaan Kriteria WEBQUAL

\begin{tabular}{|l|l|}
\hline KRITERIA WEBQUAL & $\begin{array}{l}\text { ADAPTASI } \\
\text { INSTRUMEN }\end{array}$ \\
\hline USEFULNESS & \\
\hline Informational Fit-to-Task & $\begin{array}{l}\text { Website ini menyajikan } \\
\text { informasi yang sesuai } \\
\text { dengan kebutuhan } \\
\text { saya. }\end{array}$ \\
\cline { 1 - 1 } $\begin{array}{l}\text { The information on the Web site is pretty much what I } \\
\text { need to carry out my tasks. }\end{array}$ & $\begin{array}{l}\text { Website ini } \\
\text { menyediakan fasilitas } \\
\text { yang memungkinkan }\end{array}$ \\
\cline { 1 - 1 } The Web site adequately meets my information needs. & $\begin{array}{l}\text { The information on the Web site is effective. } \\
\text { Interactivity } \\
\text { tailored information. }\end{array}$ \\
\cline { 1 - 1 } $\begin{array}{l}\text { The Web site has interactive features, which help me } \\
\text { accomplish my task. }\end{array}$ &
\end{tabular}




\begin{tabular}{|c|c|}
\hline KRITERIA WEBQUAL & $\begin{array}{l}\text { ADAPTASI } \\
\text { INSTRUMEN }\end{array}$ \\
\hline $\begin{array}{l}\text { I can interact with the Web site in order to get information } \\
\text { tailored to my specific needs. }\end{array}$ & $\begin{array}{l}\text { saya mencari informasi } \\
\text { yang saya butuhkan. }\end{array}$ \\
\hline Trust & \\
\hline I feel safe in my transactions with the Web site. & \multirow[t]{3}{*}{ Tidak dapat diadaptasi } \\
\hline I trust the Web site to keep my personal information safe. & \\
\hline $\begin{array}{l}\text { I trust the Web site administrators will not misuse my } \\
\text { personal information. }\end{array}$ & \\
\hline Response Time & \\
\hline $\begin{array}{l}\text { When I use the Web site there is very little waiting time } \\
\text { between my actions and the Web site's response. }\end{array}$ & \multirow[t]{3}{*}{$\begin{array}{l}\text { Website ini dapat } \\
\text { diakses dengan cepat }\end{array}$} \\
\hline The Web site loads quickly. & \\
\hline The Web site takes long to load. & \\
\hline \multicolumn{2}{|l|}{ EASE OF USE } \\
\hline Ease of Understanding & \multirow{4}{*}{$\begin{array}{l}\text { Website ini menyajikan } \\
\text { informasi yang mudah } \\
\text { untuk dipahami. }\end{array}$} \\
\hline The display pages within the Web site are easy to read. & \\
\hline The text on the Web site is easy to read. & \\
\hline The Web site labels are easy to understand. & \\
\hline \multicolumn{2}{|l|}{ Intuitive Operations } \\
\hline Learning to operate the Web site is easy for me. & \multirow{3}{*}{$\begin{array}{l}\text { Website ini mudah } \\
\text { untuk digunakan. }\end{array}$} \\
\hline $\begin{array}{l}\text { It would be easy for me to become skillful at using the } \\
\text { Web site. }\end{array}$ & \\
\hline I find the Web site easy to use. & \\
\hline \multicolumn{2}{|l|}{ ENTERTAINMENT } \\
\hline Visual Appeal & \\
\hline The Web site is visually pleasing. & \multirow{3}{*}{$\begin{array}{l}\text { Website ini memiliki } \\
\text { desain yang menarik. }\end{array}$} \\
\hline The Web site displays visually pleasing design. & \\
\hline The Web site is visually appealing. & \\
\hline Innovativeness & \\
\hline The Web site is innovative. & \multirow{3}{*}{$\begin{array}{l}\text { Website ini memiliki } \\
\text { desain yang inovatif. }\end{array}$} \\
\hline The Web site design is innovative. & \\
\hline The Web site is creative. & \\
\hline Flow-Emotional Appeal & \\
\hline I feel happy when I use the Web site. & \multirow{3}{*}{$\begin{array}{l}\text { Website ini } \\
\text { menyenangkan untuk } \\
\text { digunakan. }\end{array}$} \\
\hline I feel cheerful when I use the Web site. & \\
\hline I feel sociable when I use the Web site. & \\
\hline \multicolumn{2}{|l|}{ COMPLIMENTARY RELATIONSHIP } \\
\hline Consistent Image & \\
\hline $\begin{array}{l}\text { The Web site projects an image consistent with the } \\
\text { company's image. }\end{array}$ & \multirow[t]{3}{*}{$\begin{array}{l}\text { Website ini sesuai } \\
\text { dengan profil }\end{array}$} \\
\hline The Web site fits with my image of the company. & \\
\hline The Web site's image matches that of the company. & \\
\hline On-Line Completeness & \\
\hline The Web site allows transactions on-line. & \multirow[t]{3}{*}{ Tidak dapat diadaptasi } \\
\hline $\begin{array}{l}\text { All my business with the company can be completed via } \\
\text { the Web site. }\end{array}$ & \\
\hline $\begin{array}{l}\text { Most all business processes can be completed via the Web } \\
\text { site. }\end{array}$ & \\
\hline \multicolumn{2}{|l|}{ Better than Alternative Channels } \\
\hline $\begin{array}{l}\text { It is easier to use the Web site to complete my business } \\
\text { with the company than it is to telephone, fax, or mail a } \\
\text { representative. }\end{array}$ & \multirow{3}{*}{$\begin{array}{l}\text { Website ini lebih } \\
\text { memudahkan urusan } \\
\text { saya dibandingkan } \\
\text { dengan media lain. }\end{array}$} \\
\hline $\begin{array}{l}\text { The Web site is easier to use then calling an organizational } \\
\text { representative agent on the phone. }\end{array}$ & \\
\hline $\begin{array}{l}\text { The Web site is an alternative to calling customer service } \\
\text { or sales }\end{array}$ & \\
\hline
\end{tabular}


Dari hasil pemetaan didapatkan sepuluh butir pertanyaan. Setiap pertanyaan ini kemudian diukur dengan menggunakan skala Likert 4 level. Pengukuran dilakukan untuk dua hal, yaitu pengukuran tingkat kepentingan masing-masing kriteria dan pengukuran tingkat kepuasan terhadap masingmasing kriteria yang sudah diimplementasikan dalam website. Bobot pengukuran tingkat kepentingan adalah sebagai berikut:

1: Sangat Tidak Penting

2: Tidak Penting

3: Penting

4: Sangat Penting

Bobot pengukuran tingkat kepuasan adalah sebagai berikut :

1: Sangat Tidak Puas

2: Tidak Puas

3: Puas

4: Sangat Puas

\subsection{Perhitungan CSI}

Untuk mengetahui besarnya nilai CSI, maka langkah-langkah yang dilakukan adalah sebagai berikut:

1. Menentukan Mean Importance Score (MIS) dan Mean Satisfaction Score (MSS). MIS adalah rata-rata dari skor kepentingan suatu atribut. $M I S(i)=$ Jumlah skor atribut $(i) / j u m l a h$ responden

Sedangkan MSS adalah rata-rata skor untuk tingkat kepuasan yang berasal dari kinerja jasa yang dirasakan oleh pelanggan.

$$
M S S(i)=\text { Jumlah skor atribut }(i) / \text { jumlah responden }
$$

2. Menentukan Total MIS. Total MIS dihitung dari Mean Importance Score dari setiap atribut pernyataan pada kuesioner.

$$
\mathrm{Y}=\sum_{i=1}^{p} \operatorname{MIS}(i)
$$

Keterangan:

$\mathrm{Y}=$ Total MIS

$\mathrm{p}=$ jumlah atribut pernyataan pada kuesioner

3. Menentukan Total dari hasil perkalian MIS(i) dengan MSS(i)

$$
\mathrm{T}=\sum_{i=1}^{p} \operatorname{MIS}(i) x \operatorname{MSS}(i)
$$

Keterangan :

$\mathrm{T}=$ Total hasil kali MIS dengan MSS

4. Menentukan nilai Customer Satisfaction Index (CSI).

$$
\mathrm{CSI}=\frac{T}{4(Y)} \times 100 \%
$$

Nilai 4 ditentukan dari skor maksimum untuk setiap atribut.

\subsection{Interpretasi nilai CSIs}

Interpretasi dari nilai CSI yang diperoleh dari hasil perhitungan formula (5) berdasarkan (Dewi, 2015) dapat dilihat pada Tabel 2. 


Tabel 2 Interpretasi Nilai CSI (Dewi, 2015)
\begin{tabular}{|l|l|}
\hline Skor & Kriteria CSI \\
\hline$<60 \%$ & Bad \\
\hline $60 \%-75 \%$ & Fair \\
\hline $76 \%-85 \%$ & Good \\
\hline $85 \%-95 \%$ & Very Good \\
\hline$>95 \%$ & Excellent \\
\hline
\end{tabular}

\section{Evaluasi}

Berdasarkan evaluasi tingkat kepentingan dan tingkat kepuasan pencari informasi terhadap portal wisata visit garut versi mobile yang diakomodasi dalam Customer Satisfaction Index, didapatkan skor CSI sebesar 90,5\% dengan interpretasi nilai Very Good (Sangat Baik). Semua responden menyatakan kepuasannya terhadap seluruh kriteria yang dinilai, namun ada beberapa hal yang masih harus dioptimalkan yaitu : (1) penyediaan fasilitas pencarian informasi wisata (2) optimasi ukuran objek yang digunakan dalam portal untuk mempercepat sistem dalam menampilkan informasi wisata (3) penerapan Search Engine Optimation (SEO) agar informasi yang disajikan di portal wisata menjadi yang prioritas diakses oleh pencari informasi.

\section{Kesimpulan}

Pembangunan portal wisata Kabupaten Garut telah dioptimalkan dengan pengembangan versi mobile menggunakan teknologi Progressive Web Application (PWA). Hasil evaluasi kualitas layanan portal dengan menggunakan Customer Satisfaction Index (CSI) menunjukkan bahwa tingkat kepuasan pengguna informasi mencapai $90,5 \%$ yaitu Sangat Baik (Very Good).

\section{DAFTAR PUSTAKA}

Badan Pusat Statistik. (2017). Indeks Pembangunan Manusia menurut Kabupaten/Kota, 2016 (mentode Baru). Dipetik November 6, 2017, dari

https://www.bps.go.id/subjek/view/id/26\#subjekViewTab3:

https://www.bps.go.id/subjek/view/id/26\#subjekViewTab3

Barner, S. \&. (2000). WebQual: An Exploration of Web-Site Quality. Proceedings of the 8th European Conference on Information Systems, Trends in Information and Communication Systems for the 21st Century, ECIS 2000 (hal. 298-305). Vienna, Austria: ECIS 2000.

Dewi, S. K. (2015). Analisis Kepuasan Pelanggan dengan Pendekatan Metode Customer Satisfaction Indicator dan Importance Performance Analysis. Seminar Teknologi dan Rekayasa (SENTRA) (hal. 33-38). Malang: Universitas Muhammadiyah Malang.

Google Developers. (2019). Progressive Web Apps. Diambil kembali dari Google Developers: https://developers.google.com/web/progressive-web-apps

Khairul Umam, R. H. (2018). Analisa Kepuasan Pelanggan dengan Menggunakan Metode Customer Satisfaction Index (CSI) dan Importance Performance Analysis (IPA). 
Seminar Nasional Sains dan Teknologi Terapan VI 2018 (hal. 339-344). Surabaya: Institut Teknologi Adhi Tama Surabaya. 